\title{
Collection and Storage of Leukocyte-Depleted Whole Blood in Autologous Blood Predeposit in Elective Surgery Programs
}

\author{
Gerda C. Leitner ${ }^{\mathrm{a}}$ Isolde Rach ${ }^{\mathrm{a}} \quad$ Michaela Horvath $^{\mathrm{a}} \quad$ Christoph Buchta $^{\mathrm{a}} \quad$ Dieter Zakel $^{\mathrm{a}}$ \\ Guenter Weigel $^{b} \quad$ Paul Hoecker $^{\mathrm{a}} \quad$ Michael B. Fischer $^{\mathrm{a}}$ \\ a Department of Blood Group Serology and Transfusion Medicine, \\ bDepartment of Cardiothoracic Surgery, Allgemeines Krankenhaus Wien, Vienna, Austria
}

For the production and storage of autologous blood components it is recommended by the European Guidelines to follow the same rules as for the production and storage of homologous blood components [1]. The collected autologous whole blood is plasma- and leukocyte-depleted and stored as packed red blood cells (PRBC). There seems to be evidence that autologous blood, stored and re-transfused as leukocytedepleted whole blood (LD WB) has no negative impact on the patients' postoperative course [2]. In compliance with the warranted quality measures $[3,4]$ preparation of autologous LD WB is a time- and cost-sparing procedure. In order to assess the quality of LD WB units stored for 35 days, we analyzed the release of $\mathrm{K}^{+}$, lactate dehydrogenase (LDH), and free hemoglobin ( $\mathrm{fHb}$ ) into the supernatant over time and measured the increase of hemolysis and the decrease of glucose and $\mathrm{pH}$ till the end of shelf life. Special attention was paid to the intracellular adenine nucleotide content, considering the latter as surrogate markers for red cell quality [5].

25 CPDA-1-preserved LD WB units $(450 \mathrm{ml}$ whole blood, $70 \mathrm{ml}$ CPDA-1) were collected from 25 healthy male donors (median age 40 years, range 22-64 years) using the double blood bag system (MacoPharma, Toucoing, France) with an integrated filter (Leucoflex; MacoPharma). The samples were evaluated for standard metabolic quality parameters $\left(\mathrm{K}^{+}\right.$, $\mathrm{LDH}$, lactate, $\mathrm{fHb}$ in the supernatant) using a Hitachi 917 spectrometer (Boehringer Mannheim, Mannheim, Germany) and for consumption of glucose, which was analyzed enzymatically by the hexokinase assay (Olympus System Reagent; Olympus Life and Material Science Europe GmbH, Hamburg, Germany). Samples were taken immediately after leukocyte depletion and then in weekly intervals until the end of shelf life. The routine quality parameters were extended by measuring ATP, ADP and AMP as described previously [6]. LD WB met the quality requirements warranted by the Euro- pean Council [4]. Leukocyte contamination was $<1 \times 10^{6}$ in all units. The metabolic parameters $\left(\mathrm{K}^{+}, \mathrm{LDH}\right.$, lactate, $\left.\mathrm{fHb}\right)$ increased over time, but hemolysis was well below the threshold of $0.8 \%$ at the end of shelf life. A mean of $0.15 \pm 0.11 \%$ was measured after 35 days. The consumption of glucose ranged between 52 and $70 \%$ (mean \pm SEM $60 \pm 6 \%$ ). Lactate levels increased to the 8-fold of initial values accompanied by a significant decrease of $\mathrm{pH}$ from initially 7.0 to 6.56 till the end of shelf life.

The intracellular content of ATP rose within 14 days from a mean of $122 \pm 26$ to $138 \pm 33$ pmol/10 $0^{6}$ erythrocytes $(\mathrm{p}<0.05)$ and decreased thereafter. At the end of shelf life $70 \pm 18 \%$ of the initial value was found. ADP and AMP showed also an increase until day 14 and day 28 , respectively, $(\mathrm{p}<0.05)$ and remained elevated until day 35 (fig. 1).

During storage erythrocytes have to carry out certain energyrequiring processes in order to maintain membrane stability [6]. This energy is provided mainly by glycolysis and its sufficiency can be measured by the concentration of intracellular purines and the consumption of glucose [7]. A satisfying glucose reserve remained at this time. $60 \%$ of glucose was utilized and intracellular ATP values were well maintained. Simultaneously ADP and AMP levels remained elevated. Enhanced loss of ADP was found in PRBCs stored after irradiation which is known to induce membrane damage, indicating a high phosphorylation rate [6]. Taken together, elevated ADP and AMP values, well maintained intracellular ATP levels as well as acceptable hemolysis measured in stored LD WB at the end of shelf life may account for less initial membrane damage by omitting the centrifugation to split LD WB into its components.

In conclusion it can be stated that red blood cells stored as LD WB fulfil the requirements for transfusion warranted by the European Council, and adequate quality of erythrocytes

\begin{tabular}{ll}
\hline KARGER & ๑ 2005 S. Karger GmbH, Freiburg \\
Fax +49 7614520714 & Accessible online at: \\
$\begin{array}{l}\text { E-mail Information@Karger.de } \\
\text { www.karger.com }\end{array}$ & www.karger.com/tmh
\end{tabular}




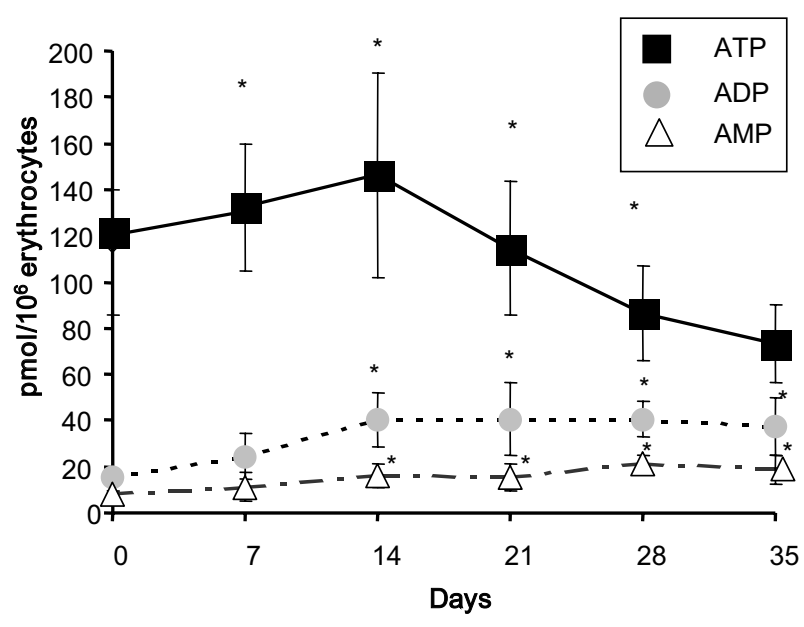

Fig. 1. Intracellular ATP $\mathbf{\square}, \mathrm{ADP} \bullet$ and AMP $\triangle$ content given in $\mathrm{pmol} / 10^{6}$ erythrocytes in LD WB units throughout the storage period of 35 days. * indicate statistical significance with a p value $<0.05$. assessed in vitro allow the assumption that the 24-hour posttransfusion recovery will not be impaired by the storage of red blood cells as LD WB. Thus, storage and transfusion of LD WB may be an option in the autologous blood predeposit.

\section{References}

1 Guide to the Preparation, Use and Quality Assurance of Blood Components, 8th ed. Strasbourg, Council of Europe Press, 2002, pp 157-160.

2 Lorentz A, Klever M, Dempfle CE, Segiet W: The type of storage of autologous blood does not influence homologous transfusion requirements in hip arthroplasty. Infus Ther Transfus Med 2001;28:336-342.

3 Guide to the Preparation, Use and Quality Assurance of Blood Components, 8th ed. Strasbourg, Council of Europe Press, 2002, p 111.

4 Singbartl G, Schleinzer W: Autologous transfusion-from euphoria to reason: clinical practice based on scientific knowledge. Transfus Med Hemother 2004;31: 199-200.

5 Hess JR, Hill HR, Oliver CK, Lippert LE, Rugg N, Joines AD. Gormas JF, Pratt PG, Silverstein EB, Greenwalt TJ: Twelve-week RBC storage. Transfusion 2003; 43:867-872.

6 Leitner GC, Neuhauser M, Weigel G, Kurze S, Fischer MB, Hocker P: Altered intracellular purine nucleotides in gamma-irradiated red blood cell concentrates. Vox Sang 2001;81:113-118. 